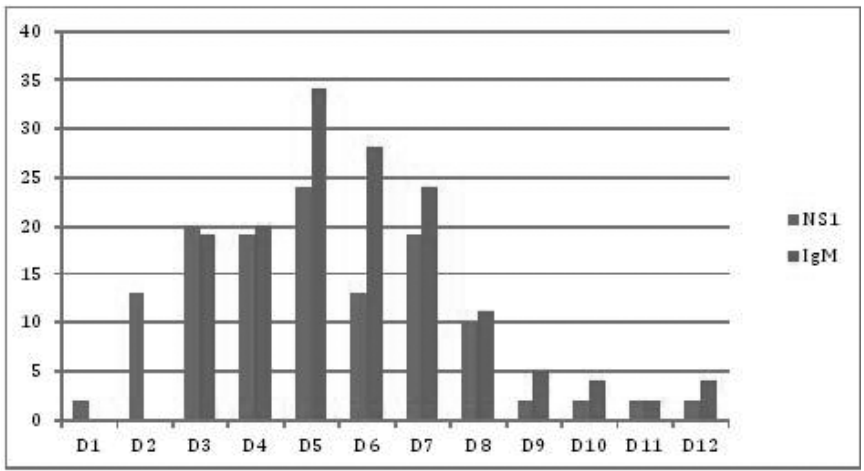

Abstract G116 Table 1 Time frame for positivity of NS1 antigen and IgM ELISA

\section{G117 CAN MEDICAL STUDENTS IN RWANDA RECALL WHAT THEY LEARNT IN ETAT + (EMERGENCY TRIAGE AND TREATMENT PLUS ADMISSION OF SICK CHILDREN) COURSE?}

doi:10.1136/archdischild-2013-304107.129

${ }^{1} \mathrm{D}$ Langer, ${ }^{2} \mathrm{P}$ Kyamanywa, ${ }^{3} \mathrm{~L}$ Tuyisenge, ${ }^{4} \mathrm{M}$ Becker, ${ }^{5} \mathrm{~T}$ Lissauer. 'London Deanery, London, UK; ${ }^{2}$ Faculty of Medicine, National University of Rwanda, Butare, Rwanda; ${ }^{3}$ Paediatric Dept, University Hospital of Kigali, Kigali, Rwanda; ${ }^{4}$ Paediatric Dept, Hinchingbrooke Hospital, Hitchingbrooke, UK: ${ }^{5}$ Paediatric Department, Imperial College Healthcare Trust, London, UK

Methods All final year medical students for last 2 years in Rwanda attended a full 5 day ETAT + course. It is designed for hospital staff, but full course was chosen as the following year the students will be working in district hospitals, usually as the most senior doctors. They took a knowledge test (multiple choice questions) at the start of the course. After the course, the same knowledge test was taken and two clinical skills scenarios were assessed, using standardised criteria. Candidates had to retake the scenario if they did not pass all the criteria and failed if they did not pass all the criteria on retesting. At the end of the academic year, 3-9 months later, their knowledge and clinical skills were reassessed with the same knowledge and clinical skills tests.

Results Between Nov 2011-May 2012, 91 medical students attended one of 4 courses. In August 2012, 81 students were re-evaluated.

The knowledge test results (figure 1): pre-course, median score was $47 \%$ (inter-quartile range 35.65 ); after the course $71 \%$ (interquartile range 63,75 ). There was a statistically significant improvement in performance (Wilcoxon matched-pairs signed rank test $p<0.0001)$. On re-evaluation, median MCQ results were $67 \%$, (inter-quartile range 52,75 ), not significantly different from postcourse performance.

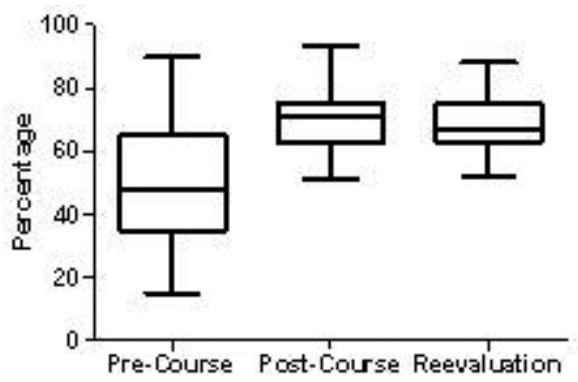

Abstract G117 Figure 1 Knowledge test results
Clinical skills assessments (Table 1) showed that 95\% passed immediately after the course, with $72 \%$ passing both at their first attempt. On re-evaluation, $74 \%$ passed, $47 \%$ at their first attempt (Chi-squared $\mathrm{p}<0.01$ ).

\begin{tabular}{|c|c|c|}
\hline \multirow[t]{2}{*}{ Table 1} & \multicolumn{2}{|l|}{ Clinical skills } \\
\hline & Post-course (n=91) & $\begin{array}{l}\text { Re-evaluation } \\
(\mathrm{n}=\mathbf{8 1})\end{array}$ \\
\hline Passed first attempt & $65(72 \%)$ & $38(47 \%)$ \\
\hline Passed second attempt & $22(24 \%)$ & $22(27 \%)$ \\
\hline Failed & $4(4 \%)$ & $21(26 \%)$ \\
\hline
\end{tabular}

Conclusion On evaluation immediately after the full ETAT+ course, there was a marked improvement in knowledge and most passed the clinical skills. The medical students coped well with the full course. On re-evaluation $3-9$ months later they retained their knowledge but clinical skills declined, showing refresher courses are required to maintain clinical skills.

\section{G118 ESSENTIAL ETAT: FEASIBILITY OF SHORT DURATION PAEDIATRIC RESUSCITATION TRAINING IN A RESOURCE- LIMITED SETTING}

doi:10.1136/archdischild-2013-304107.130

1,2L Pollock, ${ }^{3} \mathrm{~N}$ Morar, ${ }^{4} \mathrm{~B}$ Dyer, ${ }^{1,2} \mathrm{~B}$ Kampmann, ${ }^{2} \mathrm{E}$ Clarke, ${ }^{3} \mathrm{ST}$ Anderson. ${ }^{1}$ Academic Department of Paediatrics, Imperial College London, London, UK; ${ }^{2}$ Vaccinology Theme, MRC Unit: The Gambia, Fajara, The Gambia; ${ }^{3}$ Department of Clinical Services, MRC Unit: The Gambia, Fajara, The Gambia; ${ }^{4}$ Emergency Department, Royal Victoria Teaching Hospital, Banjul, The Gambia

Aims ETAT and ETAT + training courses provide comprehensive training in paediatric emergency care over 3.5-5 days and have been shown to improve outcome in resource-limited settings. However, the logistics, cost and impact on local service delivery of a five day course may limit training opportunities in some settings. In this context, we aimed to determine whether a shorter, more focused course - 'Essential ETAT' - would be feasible.

Methods Two resuscitation training courses were designed, of one or 2.5 days duration. Both courses were adapted from WHO ETAT and ETAT + training materials and included practical and lecturebased sessions on triage, cardiopulmonary resuscitation and recognition and management of key paediatric emergencies. Practical sessions in airway management, bag-valve-mask ventilation and intra-osseous needle insertion were included. There were no hospital-based sessions and newborn emergencies were not included. A short manual summarising ETAT guidelines was provided. Participants were nurses and doctors working in primary or secondary care settings in Gambia. Impact on participant knowledge was assessed by pre and post-course multiple-choice test. Participants' evaluation of the course was assessed by structured questionnaire.

Results Nineteen and 22 participants completed the 2.5 and 1 day courses respectively. Participants on both courses showed a significant improvement in post-course test scores using a paired t-test; 2.5 day course mean scores- pre12.42, post 15.63 ( $p<0.001$ ); 1 day course mean scores- pre 14.32, post $16.86(p<0.001)$. There was no significant difference in mean post-course scores $(p=0.08)$ or in mean increase in score post-course (3.21 compared to $2.54, \mathrm{p}=0.4$ ) between participants from the 2.5 day and 1 day courses respectively. Participant feedback from both courses was positive.

Conclusions The comprehensive training offered by ETAT/ ETAT + is of proven benefit. However, in settings where providing such courses is logistically difficult, focused training of shorter duration may offer a pragmatic and potentially cost-effective alternative. 